\title{
WOMEN IN MEDICINE
}

In Conjunction with McGill Feminism in Medicine

\section{Women in Medicine: Dr. May Cohen, aka "The Gender Lady"}

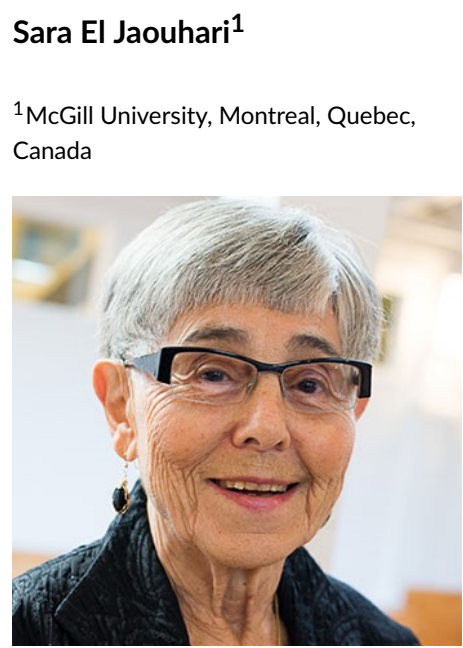

Dr. May Cohen

Correspondence

Sara El Jaouhari

Email: sara.eljaouhari@mail.mcgill.ca

Publication Date

July 29,2020

MJM 2020 (18) 6

\section{\$. McGill \\ Journal of Medicine}

www.mjmmed.com

\section{(c) (i) (2) (2)}

This work is licensed under a Creative Commons BY-NC-SA 4.0 International License.

Image from:

https://medicine.utoronto.ca/sites/default/files/cohen_may_ 2015.jpg

\section{KEYWORDS}

May Cohen, Gender Equity, Abortion Rights, Medicine

\section{Dr. May Cohen, aka "The Gender Lady"}

Some of the greatest strides seen in Canadian women's health and in gender equity in medicine can be attributed to Dr. May Cohen: an unyielding activist who dedicated her life's work to advocacy. From spearheading the development of the first Women's Health Office at McMaster University to serving as President of the Federation of Medical Women in Canada, her career is a testament to what can be achieved with a strong social conscience and unwavering determination.

Even early on in her life, one could see that Dr. May Cohen had a strong sense of resolve. Born in Montreal and raised in Toronto, she wanted to become a doctor from an early age. In one interview, Dr. Cohen recalled the moment she shared her desire to become a physician with her eighth grade teacher, who told her that "women do not become doctors." (1) Fortunately, she didn't let that dissuade her, and eventually she went on to attend the University of Toronto's Medical School as one of only fourteen women in the class. (1)

Dr. Cohen's resolve persisted as a young woman pursuing medical training before women in medicine were commonplace. In an interview on White Coat, Black Art, Dr. Cohen was asked what it was like as a medical student at a time when women formed merely $10 \%$ of the class. (2) She recalled the first day the dean came in to 
welcome the fresh-faced cohort: "He informed us that we would have to wear a tie and shave everyday. All we could do as the few women was look at our own legs." (2) Similarly, she recalled that her anatomy professor would always greet the class with "Good morning, Gentlemen." On one occasion, she decided to sit in the front row along with the other women in the class to make a statement. His greeting, however, remained the same. At the time, she wasn't yet sensitized to the discrimination and later stated she was simply happy to be amongst the chosen ten percent. (2) In 1955, Dr. Cohen went on to graduate at the top of her class-a reflection of the tenacity and perseverance that underlined the rest of her career and life.

As Dr. Cohen moved into the early part of her career, she began to take an interest in social issues that intersected with women's health. When Dr. Cohen first started practicing as a family physician in Toronto, abortion was illegal in Canada. (2) She remembered several instances where patients came to her seeking abortion services; fortunately, most of them at the time had the financial resources to travel to England, where abortion was legal. One of the most striking moments, however, was when one of her own patients was admitted to the emergency department and subsequently died from the complications of an illegal abortion. (2) For her, the young woman's death became symbolic of a larger problem, as she understood the fundamental connection between women's autonomy over their bodies and their health.

Dr. Cohen took on a more active role in advocating for women's medical rights as Canadian political landscapes shifted. In 1969, a significant change in the abortion law was passed under Trudeau's Liberal government making abortion permissible under certain circumstances. Under these laws, abortion would be legal to perform in a hospital if a committee of three physicians determined that continuing the pregnancy would endanger the mother's life or health. (3) While this was certainly a huge step forward, Dr. Cohen quickly realized that loopholes existed within the new law. Firstly, not every hospital was obliged to have an abortion committee and secondly, as 'health' and 'life' were not clearly defined in the law, it allowed greater room for interpretation resulting in some committees being more restrictive than others. (2) At the time the change was highly contentious, and many pro-choice physicians and abortion providers were targeted in violent hate crimes. $(2,3)$ Despite the risk to herself, Dr. Cohen joined the abortion decision committee at Branson Hospital in Toronto and tirelessly fought for access to legal and safe abortion for women across Canada. She strongly believed that "if someone is forced to carry a pregnancy they don't want, that is a risk to their health." (2) Since those early days, she has continued to figure prominently in the medicolegal debate on abortion laws and women's right to choose.

In addition to her advocacy work on abortion, Dr. Cohen played an active role in promoting an understanding of women's specific health needs across the country. 'Year of the Woman' was declared in 1975 and the government funded several women's health initiatives. (1) As part of one project, Dr. Cohen was invited to lead a workshop on women's health in Shelburne, Nova Scotia. While she visited, she was disappointed to realize that women living in the area did not have access to routine breast exams or pap smears. "There was no concept of 'women's health' and 'men's health' at the time, and [Dr. Cohen] believed that if you were a good doctor then you were a good doctor to both." (1) Her experience in Nova Scotia led her to question whether women's health needs were being appropriately met elsewhere in Canada. (2) A few years later, while on sabbatical in Australia, Dr. Cohen learned of an ongoing study investigating women's specific health needs in each state, which motivated her to organize a similar effort in Canada. $(1,2)$ This eventually led to her to co-found the Women's Health Office at McMaster University in 1991, which would become the nucleus of the women's health initiative in Canada. (1)

The first of its kind in any Canadian medical school, the Women's Health Office sought to educate and raise awareness of diseases that affected women differently, whether in prevalence, prognosis or therapy. (4) "When I went to medical school, the medical paradigm was that of the $70 \mathrm{~kg}$ male, who was white," she mentioned in 
one interview. "Everything in terms of dosage of drugs, in terms of prognosis, was based on that paradigm." (2) The Office strived to change this by organizing lectures on women's health to all members of the Faculty of Health Sciences, and by acting as a resource to university and community-based groups launching their own women's health initiatives. Dr. Cohen's persistence in pushing for the inclusion of women's health in the medical school curriculum eventually led to the creation of the Women's Health Inter School Curriculum Committee, a partnership spanning across five Ontario medical schools. (4) In establishing institutional recognition of women's health issues, Dr. Cohen challenged the malecentric paradigm in medicine and transformed the educational landscape for all health students in Canada.

Throughout her career, Dr. Cohen has focused on promoting an evidence-based understanding of women's issues both in health and in healthcare. As a researcher, Dr. Cohen has promoted women's health issues in areas such as breast cancer and domestic abuse. Within healthcare itself, Dr. Cohen has also played an important role in understanding the factors that have restricted equal access to the workplace. Issues of gender equality, discrimination, abuse, gender differences in practice, and the effect of having children on professional life are all areas in which Dr. Cohen has taken an active interest. $(5,6,7)$ In her article titled Cracking the glass ceiling, she states: "We know the difference that women leaders make in professional education, research and women's health care. However, we must be more rigorous in defining and understanding the factors that influence the impact that women make, including their leadership style." (8) By shedding light on such issues, Dr. Cohen has helped pave the way for the many female physicians who followed after her.

Dr. May Cohen is now retired, but her legacy continues to impact the medical community. In light of her longstanding advocacy for gender equality in medicine, she was inducted to the Canadian Medical Hall of Fame in 2016. In 2017, she was named an Officer to the Order of Canada for her "exemplary leadership in the establishment and growth of the field of women's health in Canada". (4) In 2019, the world premiere of "The Gen- der Lady: The Fabulous May Cohen," an award-winning documentary chronicling her inspirational life, aired at the Toronto Jewish Film Festival. When asked about the documentary, she said, "I want to send the message that physicians have a social responsibility, and that is what I tried to do during my career in promoting women and women's health. These were all issues of social importance that went beyond what was good for only myself." (9) Through the many accomplishments in her life and career, Dr. May Cohen has certainly exemplified the pursuit of social justice, and is a role model for current and future physicians alike.

\section{REFERENCES}

1. Faculty of Medicine, University of Toronto. Women's Health Trailblazer: Dr. May Cohen, MD'55. [Online]. Available from: https://medicine.utoronto.ca/alumni/womens-healthtrailblazer-dr-may-cohen-md55.

2. White Coat Black Art. [Online]. Available from: https://www.cbc.ca/player/play/1539433539961/.

3. Abortion rights: significant moments in Canadian history. [Online].; 2009. Available from: https://www.cbc.ca/news/canada/abortion-rights-significantmoments-in-canadian-history-1.787212.

4. Federation of Medical Women of Canada. [Online]. Available from: https://fmwc.ca/dr-may-cohen-named-as-an-officer-to-theorder-of-canada/.

5. Cook DJ,GLE,CMea. Discrimination and abuse experienced by general internists in Canada. J Gen Intern Med. 1995;(10): 565572.

6. Woodward CA WAFBCM. Time spent on professional activities and unwaged domestic work. Is it different for male and female primary care physicians who have children at home? Can Fam Physician. 1996;(42): 1928-1935.

7. Cohen M FBWCGC. Gender differences in practice patterns of Ontario family physicians. Journal of the American Medical Women's Association. 1991; 2(46): 49-54.

8. Cohen M. Women's issues-Cracking the glass ceiling Cmaj 157.12 (1997): 1713-1714. CMAJ 157.12. 1997;: 1713-1714.

9. Depko T. Daily News. [Online]. Available from: https://dailynews.mcmaster.ca/articles/may-cohen-documentaryto-premiere-at-the-toronto-jewish-film-festival/. 